\section{Long-term clinical outcomes following 3- and 4-level anterior cervical discectomy and fusion}

TO THE EDITOR: After publication of our article "Long-term clinical outcomes following 3- and 4-level anterior cervical discectomy and fusion" (J Neurosurg Spine [epub ahead of print February 19, 2016; DOI: 10.3171/2015.10.SPINE15795), we discovered 3 errors that we wish to correct.

In the Abstract, Results subsection, we stated that 71 patients underwent 3-level anterior cervical discectomy and fusion (ACDF) and 26 patients underwent 3-level ACDF. This is incorrect. The corrected sentence now reads:

Seventy-one patients who underwent 3-level $\mathrm{ACDF}$ and 26 patients who underwent 4-level ACDF were identified and followed for an average of $7.6 \pm 4.2$ years. [Boldface type added to show change.]

In the Methods section, page 2, under the heading "Study Sample," we stated that we reviewed case notes for patients who underwent ACDF between 1996 and 2012. This is incorrect. The corrected sentence now reads:

Following institutional review board approval, a retrospective review of clinical and operative notes was performed to identify all neurosurgical patients undergoing an ACDF at a single academic institution between 1996 and 2013. [Boldface type added to show change.]

In the Results section, page 3, last paragraph, we referred to patients with myelopathy when we meant weakness. The corrected sentence now reads:

At last follow-up, a significantly greater proportion of patients in the 4-level group reported axial neck pain and weakness when compared with the 3-level group (Table 3). [Boldface type added to show change.]

We apologize for these errors and appreciate the opportunity to correct our paper by publishing this erratum notice. The text of our article has been corrected online as of April 8,2016, and appears in this issue.

Rafael De la Garza-Ramos, MD Ali Bydon, MD Johns Hopkins University School of Medicine, Baltimore, MD

CORRESPONDING ARTICLE See pp 885-891. INCLUDE WHEN CITING

Published online April 8, 2016; DOI: 10.3171/2016.3.SPINE15795a.

CAANS, 2016 